\title{
Infant mortality rates and nonrenewable energy consumption in Asia and the Pacific: The mediating role of carbon emissions
}

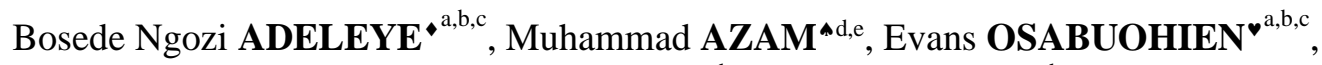 \\ Ifeoluwa OGUNRINOLA ${ }^{* a, b}$, Paul ADEKOLA ${ }^{{ }^{\mathrm{a}, \mathrm{b}}}$
}

${ }^{a}$ Department of Economics and Development Studies, Covenant University, Nigeria; ${ }^{b}$ Centre for Economic Policy and Development Research (CEPDeR), Covenant University, Nigeria; ${ }^{\mathrm{C}}$ Regional Centre of Expertise (RCE) Ogun, Nigeria

${ }^{\mathrm{d} S c h o o l ~ o f ~ E c o n o m i c s, ~ F i n a n c e ~ \& ~ B a n k i n g, ~ C o l l e g e ~ o f ~ B u s i n e s s, ~ U n i v e r s i t i ~ U t a r a ~ M a l a y s i a, ~ M a l a y s i a ; ~}$ e Department of Economics, Faculty of Business and Economics, Abdul Wali Khan University Mardan, Pakistan

\begin{abstract}
This study aligns with the 2030 United Nations Sustainable Development Goals- 3 which aim to "ensure healthy lives and promote well-being for all at all ages". It contributes to the nascent literature stream on energy-health dynamics by introducing a holistic theoretical model to empirically examine the mediation effect of carbon emissions on the relationship between nonrenewable energy and infant mortality rates. Using an unbalanced panel data on 42 Asia and the Pacific countries from 2005 to 2015 and deploying the structural equation modeling approach, the empirical results are surmised as follows: (i) in regard to the full sample of countries, nonrenewable energy indirectly increases infant mortality rates through increasing carbon emissions. In other words, carbon emissions play a partial mediation role between nonrenewable energy and infant mortality rates; and (ii) for the different income groups, carbon emissions show varying mediation effects. For example, the mediation effects of carbon emissions in lower-middle and upper-middle income countries are found to be similar to those of the full sample of countries. Therefore, based on these findings, we conclude that nonrenewable energy is an essential determinant of infant mortality rates. Policy recommendations are put forward.
\end{abstract}

Keywords: Carbon emissions; infant mortality rate; per capita income; nonrenewable energy; Asia and the Pacific region

JEL Classification: I00, I10; I15; I18; I19; N55

\footnotetext{
• Corresponding Author ngozi.adeleye@ covenantuniversity.edu.ng; ORCID: 0000-0002-1274-714X; website: https://cruncheconometrix.com.ng

^drazam75@yahoo.com; ORCID: 0000-0001-7417-3981

- evans.osabuohien@covenantuniversity.edu.ng

* ifeoluwa.ogunrinola@covenantuniversity.edu.ng

- paul.adekola@covenantuniversity.edu.ng
} 


\section{$1 \quad$ Introduction}

The search for resilient sustainable economic development is fast becoming an interesting concern among governments, policy makers, and international institutions to bolster social uplift. In fact, the excessive usage of energy, mainly from carbon associated sources is detrimental to the environment and public health. Economic development is human development [1], as human capital is directly associated to growth and is undeniably one of the most essential ingredients of economic growth and development. Human capital is considered as "a prime engine for economic growth" [2-4]. Therefore, it is essential to survey the factors that determine human capital. The available studies reveal that nonrenewable energy (NRE) and some fossils associated ailments also adversely affect human capital, but such impact ought to be investigated, which is the main objective of this study.

Energy is an imperative element of every society and undertakes a domineering part boosting socio-economic living standard of the society. Energy sources can be categorized into renewable energy (RE) and NRE sources. Whereas the main RE sources are biomass, hydro (water), wind, solar, and geothermal. These sources are limitless in supply and can be replenished/ refilled naturally. While the non-NRE sources are coal, oil, nuclear, and gas. These are scarce in supply and cannot be replaced or recycled [5]. Several erstwhile studies highlighted that the increase in the use of energy for economic activities increases a huge concern of rising environmental depletion [6,7]. To prepare more goods and services-meet the increasing energy demand at local level have enhanced the incineration of fossil fuels such as coal, gas, and oil at the industrial level and solid fuels burning at the household level. Certainly, on one hand the exploitation of fossil fuels is though adding to GDP per head but producing GHGs which affects public health on the other hand [8]. Renewable energy source has some idiosyncratic positive economic heave impacts compared to NRE. In their study, [9] mentioned 
(RE)'s technologies may perhaps be less viable compared to NRE due to a large level of preliminary capital cost.

Growing $\mathrm{CO}_{2}$ emissions unfavorably affects many health indicators ${ }^{1}$, consequently an adverse influence of health indicators lead to a reduction in human capital productivity and therefore a decrease in the socio-economic development. Health indicators such as life expectancy and infant mortality rate are among the key variables. Life expectancy is "the expectation of how long a newborn person can live on average, assuming that current mortality rates remain unchanged"; while infant mortality rate is "the number of children who expires under the age of one for every 1000 live births in a year" [10]. The existing ambient levels of air pollution in the city of Sao Paulo, Brazil are linked with mortality for people above 65 years of age for all non-accidental causes, for cardiovascular and for respiratory illnesses [11]. Evidently, environmental contamination is approaching distressing proportions globally. Environmental contaminants have numerous adversative health effects from early life, some of the utmost important detrimental influences are infant mortality, perinatal illnesses, cardiovascular illnesses, respiratory illnesses, allergies, rise in stress oxidative, endothelial dysfunction, mental illnesses, and many other destructive effects $[12,13]$. It is extensively argued that the people of the developing world can be exposed to the different harmful gases coming from the combustion of fossil fuels from production, transport, and power generation due to the absence of the clean energy. Moreover, energy use can directly or indirectly influence human health by causing air pollution, lack of safe water, and inadequate medical care infrastructures. Likewise,

\footnotetext{
${ }^{1}$ Global health indicators can be divided into directly and indirectly measure health sensations, where directly measure are (e.g., deaths, illnesses, use of services) and indirect measures are (e.g., education, poverty indicators, and societal development); these are also described to as distal and proximal indicators, respectively. According to the World Health Organization (2015) report there are total 100 Core Health Indicators are life expectancy (at birth), adult mortality rate between $15 \& 60$ years of age, under-five mortality rate, infant mortality rate.
} 
fossil fuel energy that is used in industries increases public health threats, and other environmental harms, which are deemed as national health securities [14].

Accomplishing sustainable environment poses a dominant stance in the process of national economic development. Indeed, the worsening of environmental quality can be explicated particularly by the rise in $\mathrm{CO}_{2}$, which is due to the consumption of energy resources for instance coal, natural gas, and oil. Consequently, the deterioration of the environmental quality by the use of pollutant energy sources can have a destructive effect on the quality of human life, thus, it influences the existence of humankind. Environmental pollution can also endanger the lives of mammals and detriment plants. Evidently, growing air pollution such as $\mathrm{CO}_{2}$, causes stern health problems and creates substantial economic liabilities for healthcare [15-17]. [18] expounded that several environmental factors affect mortality. Many prior studies exploring environmental effects on mortality have concentrated on air pollutants and indicated that exposure to air pollutants is connected with an increased risk of mortality [19-21].

Furthermore, [22] expounded that the World Health Organization (WHO) has found climate change as one of the biggest health hazards of the $21^{\text {st }}$ century, and air pollution as the sole leading environmental health hazard. Several erstwhile studies have underlined that the prominent cause of higher mortality rate is because of the environmental degradation which occurs due to the consumption of NRE resources for instance fossil fuels at micro-level and macro-level [23-25]. Undeniably, unregulated air pollution cause mortality from cardiac, respiratory, and other disorders [26]. Substantial death rates are connected to fossil fuel energy consumption, as combustion emissions from power generation, transport, and industry usually occur in heavily crowded regions [27]. Many other pollutant sources including biomass burning, agriculture, and residential energy usage needs be controlled to accomplish a decrease 
in mortality up to 5.55 million superfluous deaths per annum (with additional mortality decrease from condensed household air pollution). Substituting fossil by clean, RE sources could reduce the worldwide mortality by $65 \%$, and up to $84 \%$ in the U.S. [28]. Environmental pollution has direct and indirect destructive effects on aggregate output via disease and health spending, as well as reducing labour productivity, and other damaging externalities [29]. [30] confirms that excess mortality related to the COVID-19 epidemic is because of air pollution by particulate matter in Italy in the first quarter of 2020.

We have observed that most of erstwhile studies researched the link between environment, economic growth, and public health expenditure. The central focus of this study is to identify and verify the interaction between environmental degradation, infant mortality rate, and NRE consumption in the context of Asia and the Pacific region. The motivation for this study is based on the central role human capital plays in the process of economic growth and development. While the human capital indicators are affected by NRE usage and thereby carbon emissions, the broad objectives of this study are to: (1) examine if NRE has a significant impact on carbon emissions; (2) evaluate whether the impact of NRE on mortality rates is significant in the presence of the mediator (carbon emissions); (3) appraise if the impact of the mediator on mortality rates is significant in the presence of NRE; (4) determine if NRE has a significant indirect (mediated) impact on mortality rates; and (5) assess if (1) to (4) significantly differ across income groups. The remaining study is structured as follows: Section 2 deals with related prior studies on the subject under investigation. Section 3 presents data, empirical model, and estimation strategy. Section 4 interprets the empirical results and shed lights on discussion. Section 5 concludes the study.

\section{Literature Review and Hypotheses Development}


In 1997, the importance of clean and sustainable environment was first established legitimately in the Kyoto Protocol which was ratified by both developed and developing economies. The protocol detects greenhouse gases $(\mathrm{GHG})$ emissions, especially carbon dioxide $\left(\mathrm{CO}_{2}\right)$ as the leading source of global warming. Moreover, $\mathrm{CO}_{2}$ emissions from fossil fuels and industrial activities are around $65 \%$ of worldwide GHG emissions [31]. The significance of energy consumption documented by [32]is that the energy use is believed as a development gauge in the literature of energy economics. Increase in economic activities, industrialization, and growing urbanization results in an increase demand for energy consumption [33]. [34] expounded that the use of energy is vital to society and offers numerous wellbeing benefits. Though, each source of energy consumption also involves health risks. The authors have also added that the major health effects ensue to the blazing of solid fuels, biomass, and coal, mostly in the form of work-related health risks and overall air pollution. Unavailability of electricity and cleanse fuels in the world's unfortunate households is a predominantly serious risk for health. Energy accessibility is linked with health at the household level "energy security" and "energy poverty or fuel poverty", the former at the household level means a family's prospect of having sufficient energy to warmth the home during cold climate, cook food, and make cool the home during hot weather - a matter of accessibility, inexpensiveness, and capability [35], and the latter, on the other hand means financial lack in affording energy for these elementary uses [36]. Energy poverty is also related with several problems of 'economic poverty', containing poor health and adversative social consequences [37, 38].

\section{$2.1 \quad$ Nonrenewable Energy and Health Outcomes}

Also, [25] studied the influence of greenhouses gasses emissions, energy utilization, and economic activities on health risks (i.e., mortality rate and incidence of respiratory disorders) in emerging Asian countries from 1995 to 2018. The empirical evidence establishes that fossil 
fuel use, GHGs, and natural resources exhaustion are main factors to growing health risks in the long run, while the usage of clean energy and enhancement in per capita output is helping to boost the health status. Results also reveals that greenhouse gasses emission is the only substantial factor accountable for the high mortality rate and incidence of respiratory disorders in the short run. The study of [39] found that NRE (i.e., coal, oil, and gas) rise measles, air pollution, tuberculosis, and mortality rate, which consequently affect human capital in Pakistan from 1995-2017. The ARDL approach verify the long-run and short-run impacts of air pollution, fossils fuels, and diseases on human capital. The Gary Becker hypothesis and the Grossman models of [40] study found that energy predictors have a significant and negative effect on infant mortality rates in 23 African countries during 1999-2014. Moreover, empirical estimates indicate that a high pollution causes an increase in mortality rates. Using the generalized method of moments technique, [41] observed that the maximum variability of mortality could be described by carbon emission variability in Commonwealth of Independent States (CIS) economies during 1993-2018.

Hypothesis 1: Nonrenewable energy is positively related to health outcomes.

\subsection{Nonrenewable Energy and Carbon Emissions}

[42] worked on the effect of real income, NRE, and RE use on $\mathrm{CO}_{2}$ emissions for the United States from 1980-2014. Findings reveal that surges in RE use alleviate environmental degradation whereas expansions in NRE use inflate $\mathrm{CO}_{2}$ emissions. [43] detected a positive influence of population density, per capita income, and NRE sources on $\mathrm{CO}_{2}$ emissions in four South Asian countries over 1980-2013. Results also indicate, that the inverse sign of RE sources suggests that per capita $\mathrm{CO}_{2}$ emissions reduce $0.352 \%$ as $1 \%$ rise in $\mathrm{RE}$ sources. The study of [44] shows that RE use has a statistically insignificant effect on $\mathrm{CO}_{2}$ emissions in Pakistan from 1970 to 2016; and coal, and natural gas are the key contributors to the level of pollution in the country. [45] found that widespread use of energy from conventional sources 
such as burning fossil fuels has destructive impacts on environmental quality by growing the level of $\mathrm{CO}_{2}$ emissions in 13 developing Asian countries during 1980 to 2014. [46] found that boost in economic growth and fossil fuels consumption contributes to the enlargement in $\mathrm{CO}_{2}$ emissions, and thereby deteriorate the environment in the 15 developing Asian countries from 1990-2013. [47] expounded that though NRE use accelerates the aggregate production, but it is also a key source of $\mathrm{CO}_{2}$ emissions in top oil producing African economies over 1980-2015. Lastly, [29] empirically obtained a uni-directional association running from RE to carbon emanations in 21 European Union countries from 1995 to 2014. Our study fills the gap in the literature by engaging a mediation modelling approach to the health-environment dynamics in Asia and the Pacific.

Hypothesis 2: Nonrenewable energy is positively related to carbon emissions.

\subsection{Nonrenewable Energy, Carbon Emissions and Health Outcomes}

There are many studies on the interrelationship between energy, carbon emissions, and public health, for different countries, they employed different empirical methodologies, while the empirical findings have been yet fused or vague. For instance, [48] showed that a 1 percent reduction in total suspended particulates bring a 0.35 percent decrease in the infant mortality rate. [49] found a statistically positive and significant effects of enhancement socio-economic conditions on public health through pollutants such as PM10 and $\mathrm{CO}_{2}$ emissions in 60 developing countries from 1990-2010. [16] showed that $\mathrm{CO}_{2}$ emissions have an adverse impact on public health in China in the long run. [50] concluded that $\mathrm{CO}_{2}$ emissions do not have effect on health status in twelve (12) countries from the Southern African Development Community (SADC) over 2000-2008. [51] documented that industrialization enhanced the level of $\mathrm{CO}_{2}$ 
emissions in developing countries, and consequently it badly affects the pregnancy outcomes and hygienic states of adolescents. A two-way causal links has been detected between changes in infant mortality rate and increase in $\mathrm{CO}_{2}$ emissions, and between gross capital formation and changes in child mortality rate, respectively from 1971-2010. [52] tested the influence of environmental degradation measured by $\mathrm{PM}_{10}$ on infant mortality rate in Nigeria during 2000 to 2016. The empirical outcomes show that environmental degradation has significantly negative effect on infant mortality.

Hypothesis 3: Carbon emissions is positively related to health outcomes.

Hypothesis 4: Carbon emissions mediates the relationship between nonrenewable energy and health outcomes.

\section{Variables, Empirical Model and Analytical Schema}

\subsection{Variables and Classifications}

This study uses an unbalanced panel data of six variables on 42 countries $^{2}$ located in Asia and the Pacific region from 2005 to 2015. The variables which are sourced from the World Bank (2020) World Development Indicators (WDI). Infant mortality (MINF) is the outcome variable, the main explanatory variable is nonrenewable energy per capita $(E N U P C)$; the mediator variable is carbon emissions per capita $(C O 2 P C)$. We include two covariates: female secondary school enrolment (SECF), and access to basic sanitation (BSAN). Under-5 mortality (MU5) rates is included used to test the robustness of the results.

On a priori expectations, nonrenewable energy consumption is expected to yield asymmetric effects on mortality rates. The impact will be positive, if increased use of unfriendly energy sources causes increased environmental pollution and eventually leads to deaths of infants and

\footnotetext{
${ }^{2}$ See Appendix Table A1 for the list of countries and income classifications.
} 
under-5 children. However, the impact is negative when nonrenewable energy sources are channelled to power health-sustaining outcomes thereby cutting down deaths of infants and children. The effect of carbon emissions on child mortality is expected to be positive as environmental pollution is hazardous to health. As female secondary education improves, it is expected that child mortality rates drop since more knowledgeable mothers are expected to understand the essentials of childcare and upbringing better than those who hold little or no education. Better sanitation is expected to reduce mortality rates. Table 1 details the variables and their respective a priori expectations.

\begin{tabular}{cllc}
\multicolumn{2}{c}{ Table 1} & Variables Description and Expected Signs & \\
\hline S/No. & Code & Short Definition & Expected signs \\
\hline 1 & MINF & Number of infant deaths & Not Applicable \\
2 & MU5 & Number of under-five deaths & N/A \\
3 & $E N U P C$ & Energy use (kg of oil equivalent per capita) & $+/-$ \\
4 & CO2PC & CO2 emissions (metric tons per capita) & + \\
5 & BSAN & People using at least basic sanitation services (\% of population) & - \\
6 & SECF & School enrolment, secondary, female (\% gross) & - \\
\hline
\end{tabular}

Source: Authors' Compilations from the World Bank (2020) World Development Indicators (WDI)

We proceed to show the measures of central tendency and correlation among the variables in Table 2. With the emphasis on the indicators of interest, the average infant mortality rate for the region is $27.07 \%$ and the standard deviation of 16.92 shows that the countries are widely dispersed from the sample average. Japan shows the lowest in 2013 to 2015 with 2.1 while Pakistan has the highest infant mortality at $79 \%$ in 2005. Singapore show to have the lowest under-5 mortality rate at $27 \%$ for years 2013 to 2015 while the country with the is Pakistan at $99.8 \%$ in 2005 . The mean under-5 mortality rate is 33.27 and the standard deviation of 21.7 evidences wide deviation from the mean. The mean of carbon emissions is 4.17 with a standard deviation of 5.12. Nepal consistently shows the lowest emissions per capita from 2005 to 2009 
averaging between 0.09 and 0.161 while Brunei shows the highest from 2007 to 2014 averaging between 19.29 and 24.63. Lastly, the sample mean energy per capita is 2079.99 with a standard deviation of 2182.92 which reveals that the countries are widely dispersed from the mean. Timor-Leste steadily shows the lowest emissions per capita from 2006 to 2008 averaging between 58.05 and 58.85 while Brunei Darussalam shows the highest from 2006 to 2014 averaging between 6074.57 to 9837.45 . (See Appendix Table A2 for detailed summary statistics across the income groups).

Table 2 Summary Statistics and Correlation Analysis

\begin{tabular}{lcccc|cc}
\hline & \multicolumn{3}{l}{ Summary Statistics } & & \multicolumn{2}{c}{ Correlation Analysis } \\
\cline { 2 - 7 } Variable & Mean & Std. Dev. & Min & Max & lnMINF & lnMU5 \\
\hline MINF $_{\text {it }}$ & 27.074 & 16.916 & 2.1 & 79 & 1.000 & \\
MU5 $_{\text {it }}$ & 33.272 & 21.715 & 2.7 & 99.8 & $0.998 * * *$ & 1.000 \\
ENUPC $_{\text {it }}$ & 2079.991 & 2182.923 & 58.046 & 9837.447 & $-0.712 * * *$ & $-0.712 * * *$ \\
CO2PC $_{\text {it }}$ & 4.17 & 5.123 & 0.098 & 24.627 & $-0.643 * * *$ & $-0.655 * * *$ \\
BSAN $_{\text {it }}$ & 73.784 & 24.905 & 14.131 & 100 & $-0.563 * * *$ & $-0.581 * * *$ \\
SECF $_{i t}$ & 78.246 & 23.569 & 26.892 & 145.888 & $-0.690 * * *$ & $-0.701 * * *$ \\
\hline N
\end{tabular}

Note: $* * *$ denotes statistical significance at the $1 \%$ level; MINF $=$ infant mortality rates; MU5 $=$ under-5 mortality rate; $\mathrm{CO} 2 \mathrm{PC}=$ carbon emissions per capita; $\mathrm{ENUPC}=$ nonrenewable energy per capita; $\mathrm{BSAN}=$ access to basic sanitation; SECF $=$ female secondary school enrolment; $\ln$ = natural logarithm.

Source: Authors' Computations

The right-hand side of Table 2 details the pairwise correlation ${ }^{3}$, which measures the relative association among the regressors and dependent variables. Using the natural logarithmic transformation of the variables, except for total natural resource rents which shows a statistically significant positive association at the $1 \%$ level, the regressors have statistically significant negative relationships with mortality rates. These provide some evidence that as the

\footnotetext{
${ }^{3}$ See Appendix A3 for detailed correlation matrix
} 
indices of these regressors increase, mortality rates decline. However, it becomes imperative to subject these finding to rigorous econometric tests (see Section 4).

\subsection{Analytical Schema}

This study argues that because nonrenewable energy naturally discharges carbon dioxide, methane, and other gasses into the atmosphere it contributes to changing climate patterns that invariably affect food production, animal ecosystems, human health and essential biodiversity within habitats. In other words, the planet is heated as more nonrenewable fuel is burned causing adverse health outcomes. Another dimension to this nonrenewable energy-emissions path is that fossil fuel which is one of the sources of nonrenewable energy leads to increase in carbon dioxide emissions in the atmosphere considered to be the primary source of "greenhouse" gas effect that causes environmental degradation with attendant harmful health aftermaths.

Hence, the conceptual framework in Figure 3 shows that the impact of nonrenewable energy consumption $(\mathrm{X})$ on mortality rate $(\mathrm{Y})$ is not somewhat direct but mediated via a third variable (M). The discourse is probed on whether environmental degradation mediates the impact of nonrenewable energy consumption on mortality rates. That is, does nonrenewable energy consumption exert a significant indirect (mediated) effect on mortality rates? In this energymortality rate framework, a third variable is added to the analysis of the initial $\mathrm{X} \rightarrow \mathrm{Y}$ relation in order to improve understanding of the connection or to determine if the link is spurious. Mediation analysis is a method to increase information obtained from a research study when measures of the mediating process are available. A mediating variable improves understanding of such a relation because it is part of the causal sequence of $\mathrm{X} \rightarrow \mathrm{M} \rightarrow \mathrm{Y}$. Such that, nonrenewable energy $\rightarrow$ carbon emissions $\rightarrow$ mortality rates. 


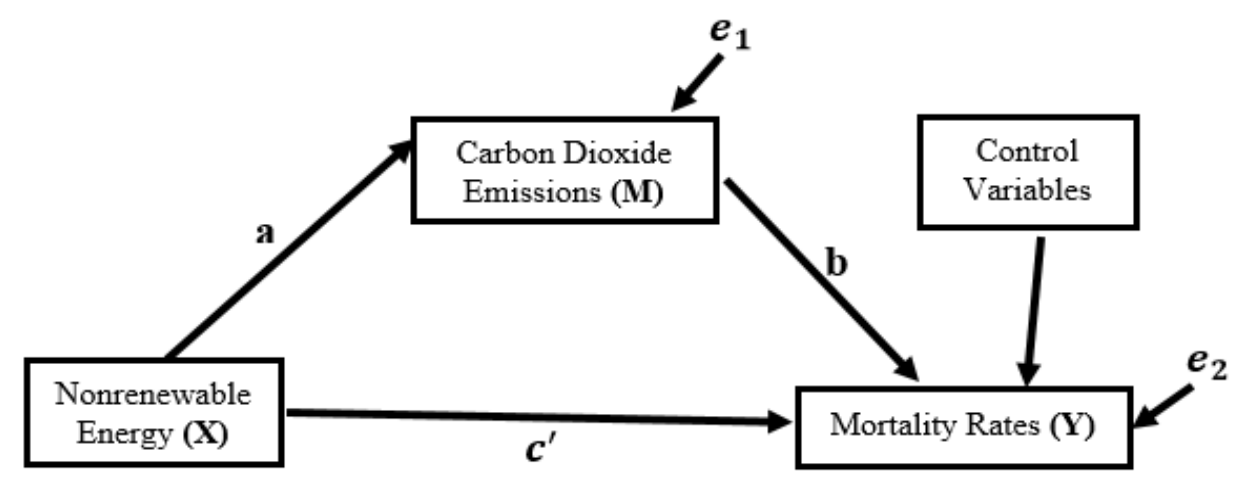

Figure 3: Mediation modelling of nonrenewable energy, carbon emissions and mortality rates. Source: Authors 'construction

Figure 3 uses the notation most widely applied in mediation modeling $[53,54,55,56,57]$ (MacKinnon et al., 2007; Baron \& Kenny, 1986; Kenny et al. 1998; Judd \& Kenny, 1981a,b), with $\boldsymbol{a}$ representing the relation of nonrenewable energy to carbon dioxide emissions, $\boldsymbol{b}$ representing the relation of carbon dioxide emissions to mortality rates adjusted for nonrenewable energy, and $\boldsymbol{c}^{\prime}$ the relation of nonrenewable energy to mortality rates adjusted for carbon dioxide emissions. The symbols $\boldsymbol{e}_{1}$ and $\boldsymbol{e}_{2}$ represent residuals in the carbon dioxide emissions and mortality rates models, respectively. The equations and coefficients corresponding to Figure 3 are discussed in section 3.3. For now, note that there is a direct effect relating nonrenewable energy to mortality rates and a mediated effect by which nonrenewable energy indirectly affects mortality rates through carbon dioxide emissions.

\subsection{Empirical Models}

As discussed in Section 2, supporting empirical evidences [48, 51, 49, 50, 52] (Chay \& Greenstone, 2003; Sinha, 2014; Fotourechi, 2016; Mutizwa \& Makochekanwa, 2015; Adedotun et al., 2018) showcase the links between emissions and health outcomes and between nonrenewable energy and health. This study connects the distinct relationships by conjuring a mediation hypothesis by which carbon emissions arbitrates the impact of nonrenewable energy 
on infant mortality rates. In other words, attempt is made to evaluate the direct and indirect effects of nonrenewable energy consumption on infant mortality rate using the mediation approach. There are three major approaches to statistical mediation analysis: (a) causal steps, (b) difference in coefficients, and (c) product of coefficients [53] (MacKinnon et al., 2007). This study uses the product of coefficients approach and specify three models:

$$
\begin{aligned}
& M_{I N F_{i t}}=\psi_{0}+\psi_{1} E N U P C_{i t}+\psi_{2} Z_{i t}^{\prime}+\gamma_{t}+e_{i t} \\
& \operatorname{CO} P C_{i t}=\eta_{0}+\eta_{1} E N U P C_{i t}+\eta_{2} Z^{\prime}{ }_{i t}+\gamma_{t}+\tau_{i t} \\
& M I N F_{i t}=\alpha_{0}+\alpha_{1} E N U P C_{i t}+\alpha_{2} \operatorname{CO}_{2} P C_{i t}+\alpha_{3} Z_{i t}^{\prime}+\gamma_{t}+v_{i t}
\end{aligned}
$$

In the aforementioned three empirical models, Equations (1) and (3) are the determinative equations of the infant mortality rate and Equation (2) is the determinative equation of carbon emissions where, $\psi_{0}, \eta_{0}$, and $\alpha_{0}$ are intercepts, $M I N F$ is the dependent variable measured by mortality rates for infants; ENUPC is the independent variable measured by nonrenewable energy per capita; $C O 2 P C$ is the mediator measured by carbon emissions per capita; $Z^{\prime}$ is a vector of covariates that affect mortality rates (female secondary education and access to basic sanitation); $\gamma_{t}$ is the time fixed effect; $e_{i t}, \tau_{i t}$, and $v_{i t}$ are the random disturbances. In simple terms, $\Psi_{\mathbf{1}}$ in Equation (1) is the coefficient relating the nonrenewable energy to mortality rates; $\boldsymbol{\alpha}_{\mathbf{1}}$ Equation (3) is the coefficient relating nonrenewable energy to mortality rates adjusted for the mediator, $\boldsymbol{\alpha}_{2}$ is the coefficient relating the mediator to mortality rates adjusted for nonrenewable energy, $\boldsymbol{\eta}_{\mathbf{1}}$ Equation (2) is the coefficient relating nonrenewable energy to the mediator, carbon emissions. Equations (1), (2) and (3) which are depicted in Figure 3 capture the respective $\boldsymbol{c}^{\prime}, \boldsymbol{a}$, and $\boldsymbol{b}$ paths.

The coefficient $\boldsymbol{\Psi}_{\mathbf{1}}$ indicates the total effect of the nonrenewable energy consumption on mortality rates. The coefficient $\boldsymbol{\alpha}_{\mathbf{1}}$ in represents the direct effect of the nonrenewable energy 
consumption on the mortality rate controlling for the influence of carbon emissions. The indirect $^{4}$ (mediation) effect equates to $\boldsymbol{\eta}_{\mathbf{1}} * \boldsymbol{\alpha}_{\mathbf{2}}$ using the product coefficient approach and the total effect is equal to the sum of the mediation effect and direct effect, i.e. $\boldsymbol{\Psi}_{1}=\left(\boldsymbol{\eta}_{1} * \boldsymbol{\alpha}_{2}\right)+$ $\boldsymbol{\alpha}_{1}$. Note that the mediation equations may be altered to incorporate additional covariates. To check for results robustness, under-5 mortality rate is used as the outcome variable to observe if the empirical outcomes are sustained. Lastly, to engage the sub-sample analysis by income groups, the data is categorised into 3 groups of High Income, Lower-Middle Income and Upper-Middle Income countries.

\section{Numbering starts from [58]}

\subsection{Estimation Approach}

This paper uses the mediation modeling approach within the structural equation modeling (SEM) framework to address the study objectives. SEM is widely used in social, behavioural and economic sciences to evaluate linear relationships among variables. Several overviews and variations of SEM can be found in [58] Aigner and Goldberger (1977), [59] Goldberger and Duncan (1973), [60] Saris and Stronkhorst (1984), [61] Saris (1980), [62] Anderson (1984), [63] Jöreskog (1981), [64] Bentler (1986), [65] Satorra (1990), and [53] Mackinnon et al (2007) to mention a few. The mediation modeling technique, on the other hand, handles how the predictor variable $X$ impacts the outcome variable Y [66, 67, 54] (Hayes, 2009, 2013; Baron and Kenny, 1986). [68] Edelman et al. (2005) and [69] Hojnik et al. (2018) explain that mediation equations specify the existence of a significant intervening mechanism (in our case, carbon emissions) between the predictor variable (nonrenewable energy consumption) and the outcome variable (infant mortality rate). As such, the mediator variable (carbon emissions)

\footnotetext{
${ }^{4}$ Mediation effect exists if the coefficients of the nonrenewable energy $\left(\boldsymbol{\eta}_{\mathbf{1}}\right)$ and carbon emissions $\left(\boldsymbol{\alpha}_{\mathbf{2}}\right)$ are statistically significant.
} 
accounts for a significant proportion of the relationship between the nonrenewable energy and the outcome variable.

Given the above, the data is analyzed using the structural equation sem routine in Stata version 16. SEM is chosen because of its precision for producing unbiased estimates of mediation impacts [70] (Cheung \& Lau, 2008). Adapting the two-step method recommended by [71] Anderson and Gerbing (1988), the structural and regression models are estimated in separate steps. First, a structural model representing the hypothesized structural relationship between nonrenewable energy and carbon emissions is evaluated (that is, Equation 2). Second, the regression model is analyzed to test the adequacy of the hypothesized relation [Equation 3]. In addition, based on the non-normal distribution of the data, the mediation (indirect) effect is tested using the Satorra-Bentler robust standard errors technique [65, 64] (Satorra, 1990; Bentler, 1986). This approach is justified in obtaining parameter estimates such as fitting the model and evaluating the estimates' sampling variability as well as the null distribution of test statistics. Lastly, the goodness-of-fit of both models is evaluated. To know if the data fits well with the hypothesized model, three critical fit indices widely used in structural equation modeling analysis are applied: the comparative fit index ([72] Bentler, 1990), Tucker-Lewis index [73, 74] (Bentler \& Bonett, 1980; Tucker \& Lewis, 1973) and root mean square error of approximation [75, 76] (Steiger, 1990; Steiger \& Lind, 1980). RMSEA is an absolute fit index, in that it assesses how far a hypothesized model is from a perfect model. On the contrary, CFI and TLI are incremental fit indices that compare the fit of a hypothesized model with that of a baseline model (i.e., a model with the worst fit).

\section{$4 \quad$ Results and Discussions}


This section presents empirical findings which fill essential gaps in the health-energy literature on Asia and the Pacific by showcasing findings on whether carbon emissions mediate the impact of nonrenewable energy on mortality rates and whether this impact differs across income groups. Estimations begin with the structural and regression models in Table 3 followed by the decomposition of effects and diagnostics in Table 4. Corresponding robustness results are displayed in Tables A4 and A5 while Table 5 summarizes the validation of the hypotheses. Results are interpreted in turns.

\subsection{Full Sample and Income Groups Results, Main Analysis}

From the structural model in the upper part of Table 3, the coefficient of ENUPC is positive and statistically significant at the $1 \%$ level across all model specifications. This indicates that a percentage change in nonrenewable energy significantly increases carbon emissions by 1.13 , 1.23, 1.084, and 1.083 in the full sample, high, lower-middle and upper-middle income countries, respectively, on average, ceteris paribus. This outcome aligns with related studies [44, 46, 47, 77, 78] (Zaidi et al. 2018; Hanif et al. 2019; Awodumi \& Adewuyi, 2020; Nathaniel \& Adeleye, 2021; Adeleye et al. 2021). From the regression model with MINF as the dependent variable, the coefficient of ENUPC is negative and statistically significant at the $1 \%$ and $5 \%$ levels for the full sample and upper middle income countries. This suggests that a percentage change in nonrenewable energy significantly decreases infant mortality rates by 0.52 and 0.79 per cent for the full sample and upper-middle income countries, respectively, on average, ceteris paribus. This outcome contradicts [25, 39] Anser et al. (2020) and Asghar et al. (2020).

Table 3 Empirical Results (Full Sample and Income Groups)

\begin{tabular}{lcccc}
\hline \multirow{2}{*}{ Variables } & Main & High Income & Lower-Mid Inc & Upper-Mid Inc \\
\cline { 2 - 5 } & {$[1]$} & {$[2]$} & {$[3]$} & {$[4]$} \\
\cline { 2 - 5 } & \multicolumn{5}{c}{ Structural Model: Dep. Var: lnCO2PC } \\
\hline lnENUPC $_{\mathrm{it}}$ & $1.1309 * * *$ & $1.2313^{* * *}$ & $1.0841^{* * *}$ & $1.0830^{* * * *}$ \\
& $(32.59)$ & $(135.81)$ & $(10.88)$ & $(28.05)$
\end{tabular}




\begin{tabular}{|c|c|c|c|c|}
\hline Constant & $\begin{array}{c}-7.1204 * * * \\
(-26.77) \\
\end{array}$ & $\begin{array}{c}-8.1194 * * * \\
(-117.27) \\
\end{array}$ & $\begin{array}{c}-6.8692 * * * \\
(-10.71) \\
\end{array}$ & $\begin{array}{c}-6.5135 * * * \\
(-21.51) \\
\end{array}$ \\
\hline \multicolumn{5}{|c|}{ Regression Model: Dep. Var: $\ln M I N F_{i t}$} \\
\hline $\operatorname{lnENUPC} \mathrm{it}_{\mathrm{t}}$ & $\begin{array}{c}-0.5222 * * * \\
(-8.02)\end{array}$ & $\begin{array}{c}0.2588 \\
(0.82)\end{array}$ & $\begin{array}{c}-0.0238 \\
(-0.21)\end{array}$ & $\begin{array}{c}-0.7859 * * \\
(-2.21)\end{array}$ \\
\hline $\operatorname{lnCO} 2 \mathrm{PC}_{\mathrm{it}}$ & $\begin{array}{c}0.0878^{*} \\
(1.76)\end{array}$ & $\begin{array}{c}-0.4708^{*} \\
(-1.90)\end{array}$ & $\begin{array}{c}0.1136^{* *} \\
(2.04)\end{array}$ & $\begin{array}{c}0.5749 * * \\
(2.08)\end{array}$ \\
\hline $\operatorname{lnSECFit}$ & $\begin{array}{c}-0.8190 * * * \\
(-7.96)\end{array}$ & $\begin{array}{c}0.6938 * * \\
(2.53)\end{array}$ & $\begin{array}{c}-0.7392 * * * \\
(-6.57)\end{array}$ & $\begin{array}{c}0.9073 \\
(1.52)\end{array}$ \\
\hline $\operatorname{lnBSAN}{ }_{\mathrm{it}}$ & $\begin{array}{c}0.0309 \\
(0.24)\end{array}$ & $\begin{array}{c}-23.6148 * * * \\
(-19.63)\end{array}$ & $\begin{array}{c}-0.1588 \\
(-1.31)\end{array}$ & $\begin{array}{c}-2.0540 * * * \\
(-6.32)\end{array}$ \\
\hline Constant & $\begin{array}{c}9.9347 * * * \\
(12.19)\end{array}$ & $\begin{array}{c}105.8284 * * * \\
(20.25)\end{array}$ & $\begin{array}{c}7.4410 * * * \\
(8.77)\end{array}$ & $\begin{array}{c}12.7425^{* * * *} \\
(5.00)\end{array}$ \\
\hline Observations & 171 & 171 & 171 & 171 \\
\hline Log-likelihood & -561.91 & -142.4754 & -142.4754 & -142.4754 \\
\hline Wald Test $\left(\operatorname{lnCO} 2 \mathrm{PC}_{\mathrm{it}}\right)$ & $1062.16^{* * *}$ & $18445.12^{* * *}$ & $118.37 * * *$ & $786.65 * * *$ \\
\hline Wald Test $\left(\operatorname{lnMINF} F_{i t}\right)$ & $334.46 * * *$ & $1709.94 * * *$ & $94.12 * * *$ & $150.48 * * *$ \\
\hline
\end{tabular}

Note: ***,**, and * denote statistical significance at the $1 \%, 5 \%$, and $10 \%$ levels, respectively; Estimations with Satorra-Bentler standard errors; $\ln =$ natural logarithm; MINF = infant mortality rates; MU5 = under-5 mortality rate; $\mathrm{CO} 2 \mathrm{PC}=$ carbon emissions per capita; $\mathrm{ENUPC}=$ nonrenewable energy per capita; $\mathrm{SECF}=$ female secondary school enrolment; BSAN = access to basic sanitation..

Source: Authors' Computations

Also, the coefficient of $C O 2 P C$ is negative and statistically significant at the $10 \%$ level for high income countries while positive and statistically significant at the $10 \%$ and $5 \%$ levels for the full sample, lower-middle and upper-middle income countries. This shows that while emissions decrease mortality rates in high income countries the reverse is the case for other specifications. The negative outcome contradicts expectations while the positive outcomes align with [41] Rasoulinezhad et al. (2020). On the control variables, basic sanitation and female secondary education evidence mortality-decreasing properties for the full sample and lower-middle income countries [40] (Shobande, 2020) but education exacerbates mortality rate in high income countries. For the most part, these findings align with a priori expectations

\subsection{Total, Direct, and Indirect (Mediation) Effects}

The results shown in the upper part of Table 4 decompose the total effects into direct and mediation effects. The direct effects are represented by the coefficient of ENUPC on mortality 
rate as interpreted in section 4.1. This paper's contribution is highlighted by its findings on the mediation effects. We show that the mediation effect is negative and statistically significant at the $10 \%$ level for high income countries while positive and statistically significant at the $10 \%$ and 5\% levels for the full sample, lower-middle and upper-middle income countries. This imply that nonrenewable energy indirectly reduces mortality rates in high income countries but increases for the full sample, lower-middle and upper-middle income countries. These are significant incursions into the health-environment literature. The total effect is the sum of the direct and indirect effects who intuitive interpretation is that overall, nonrenewable energy exert mortality-reducing outcomes in three out of four models supporting Figure 2, in hindsight.

Table 4 Decomposition of Effects and Diagnostics, Main Results

\begin{tabular}{lcccc}
\hline \multirow{2}{*}{ Nonrenewable energy consumption } & Full Sample & High & Lower-mid & Upper-mid \\
\cline { 2 - 5 } & Standardized & Standardized & Standardized & Standardized \\
\hline Direct Effects & $-0.522^{* * *}$ & 0.2588 & -0.024 & $-0.786^{* *}$ \\
z stat & $(-8.02)$ & $(0.82)$ & $(-0.21)$ & $(-2.21)$ \\
Mediation Effects & $0.099^{*}$ & $-0.579^{*}$ & $0.123^{* *}$ & $0.623^{* *}$ \\
z stat & $(1.76)$ & $(-1.89)$ & $(2.25)$ & $(2.15)$ \\
Total Effects & $-0.423^{* * *}$ & $-0.321^{* * *}$ & 0.099 & $-0.163^{*}$ \\
z stat & $(-10.08)$ & $(-14.80)$ & $(1.24)$ & $(-1.75)$ \\
\hline Diagnostics/Goodness-of-fit & Full Sample & \multicolumn{3}{c}{ Income Groups } \\
\hline RMSEA & 0.016 & & 0.018 & \\
Comparative fit index (CFI) & 0.994 & & 0.981 & \\
Tucker-Lewis index (TLI) & 0.981 & & 0.934 & \\
Standardized root mean squared residual & 0.018 & & 0.044 & \\
Coefficient of determination (CD) & 0.922 & & 0.915 & \\
\hline
\end{tabular}

Note: $* * *, * *$, and $*$ denote statistical significance at the $1 \%, 5 \%$, and $10 \%$ levels, respectively; Estimations with Satorra-Bentler standard errors; RMSEA = Root mean squared error of approximation.

Source: Authors' Computations

For the diagnostics, having deployed the Satorra-Bentler robust standard errors, the goodnessof-fit of the models is evaluated. [79] Hu and Bentler (1999) suggested the following criteria 
for a good model fit: RMSEA $<0.06$, CFI and TLI $>0.95$ and our models align with these thresholds. The CD mirrors the R-squared and indicates that about $92 \%$ variation in mortality rate is explained by the regressors. Overall, we conclude that the specified models are not statistically different from the hypothesized models. To test the robustness of our results, the dependent variable is replaced with under-5 child mortality rate and the outcomes shown in Appendix Tables A4 and A5 are not significantly different from those of Tables 3 and 4. Hence, the initial findings and discussions hold.

\subsection{Hypotheses Validation}

The summary of the regression analyses of the four hypotheses tested in the study is shown in Table 5. Hypothesis 1 is rejected for the full sample and upper-middle income countries while partially sustained ${ }^{5}$ and partially rejected ${ }^{6}$ for high income and lower-middle income countries. Hypothesis 2 is sustained for all. Hypothesis 3 is rejected for high income countries but sustained for others. Lastly, hypothesis which is the contribution of this study is rejected for high income countries but sustained for others.

\section{Table 5 Hypotheses Validation}

\begin{tabular}{lccccc}
\hline Hypotheses & FS & HI & LMI & UMI \\
\hline $\begin{array}{l}\text { Hypothesis 1: Nonrenewable energy is positively related to health } \\
\text { outcomes (direct effect). }\end{array}$ & R & PS & PR & R \\
$\begin{array}{l}\text { Hypothesis 2: Nonrenewable energy is positively related to carbon } \\
\text { emissions. }\end{array}$ & S & S & S & S \\
$\begin{array}{l}\text { Hypothesis 3: Carbon emissions is positively related to health } \\
\text { outcomes. }\end{array}$ & S & R & S & S \\
$\begin{array}{l}\text { Hypothesis 4: Carbon emissions mediates the relationship between } \\
\text { nonrenewable energy and health outcomes (direct/indirect effect). }\end{array}$ & S & R & S & S \\
\hline
\end{tabular}

Note: FS = Full Sample; HI = High Income; LMI = Lower-Middle Income; UMI = Upper-Middle Income; R = Rejected; PR = Partially rejected; $\mathrm{S}=$ Sustained; PS = Partially sustained

Source: Authors' Compilation

\footnotetext{
${ }^{5}$ Partially sustained $=$ coefficient is positive but statistically not significant.

${ }^{6}$ Partially rejected $=$ coefficient is negative but statistically not significant.
} 


\section{Conclusion and Policy Recommendations}

The nexus between energy-emissions, emissions-health and energy-health have been well researched with varying and inconclusive outcomes. Though the energy-health nexus has been explored, However, the existing literature has not explored the nexus to the best of our knowledge, no single study to date has explored the mediating role of carbon emissions in the relationship between nonrenewable energy and mortality rates. Our study addresses this research gap. We contribute to the emerging literature stream on energy-emissions-health dynamics by introducing a theoretical model to empirically examine the mediation effect of carbon emissions on the relationship between nonrenewable energy and mortality rates. Using an unbalanced panel data on Asia and the Pacific countries from 2005 to 2015 and deploying the structural equation modeling approach, the results are surmised as follows: (i) in regard to the full sample of countries, nonrenewable energy potentially indirectly increases infant mortality rates through increasing carbon emissions. In other words, carbon emissions play a partial mediation role between nonrenewable energy and infant mortality rates; and (ii) for the different income groups, carbon emissions show varying mediation effects. For example, the mediation effects of carbon emissions in lower-middle and upper-middle income countries are found to be similar to those of the full sample of countries. Therefore, based on these findings, we conclude that nonrenewable energy is an essential determinant of infant mortality rates. These findings suggest that since non-renewable energy indirectly increases infant mortality rates through increasing carbon emissions measures towards shifting to renewable energy sources need to be pursued by the various governments and stakeholders in the heath sector. This is because wind, solar, and hydroelectric systems generate electricity with no associated air pollutants. Geothermal and biomass systems emit some air pollutants, though total air emissions are generally much lower than those of fossil fuel, petroleum, coal and natural 
gas. In other words, adopting environmental quality policies will further reduce infant mortality rates in these countries.

\section{Declarations}

Funding: This research received no external funding.

Acknowledgment: The authors acknowledge the support of Covenant University Centre for Research, Innovation and Development for providing an enabling environment to engage this research.

Author Contributions: Conceptualization, BNA; Methodology and Investigation, BNA; Formal Analysis, BNA; Writing- Original draft preparation, MA; Review \& Editing, EO, IO and PA

Data Availability Statement: The data presented in this study are available on request from the corresponding author. The data are not publicly available due to privacy.

Conflicts of Interest: The authors have no competing interests.

\section{References}

1. Rashid, S. (2000). Economic Policy for Growth: Economic Development is Human Development. Kluwer Academic Publisher, Boston, MA.

2. Abbas, Q., \& Mukhtar, E. M., (2001). The role of human capital in economic growth: a comparative study of Pakistan and India. The Pakistan Development Review, 39(4), 451-473

3. Azam, M. \& Ahmed, M. A., (2015). Role of human capital and foreign direct investment in promoting economic growth: Evidence from Commonwealth of Independent States. International Journal of Social Economics, 42(2), 89-111

4. Ehrlich, I., \& Pei, Y., (2020). Human capital as engine of growth: the role of knowledge transfers in promoting balanced growth within and across countries. Asian Development Review, 37(2) 225263

5. Matthew R. F., (2019). Environmental Biology. Publisher: Open Oregon Educational Resources. EBOOK ISBN: 978-1-63635-036-3. Available at https://openoregon.pressbooks.pub/envirobiology/

6. Phong L.H., Van D.T.B., \& Bao H.H.G. (2018). The role of globalization on $\mathrm{CO} 2$ emission in Vietnam incorporating industrialization, urbanization, GDP per capita and energy use. International Journal of Energy Economics and Policy, 8: 275-283

7. McConnell, C. R., Brue S.L., \& Flynn S.M. (2018). Natural resource and energy Economics: Principles, Problems, and Policies (eighth ed.), The McGraw-Hill, pp. 312-334

8. Bailis R, Ezzati M, \& Kammen DM (2005) Mortality and greenhouse gas impacts of biomass and petroleum energy futures in Africa. Science, 308(5718):98-103

9. Kahia, M., M.S.B. Aïssa, \& L. Charfeddine (2016). Impact of renewable and non-renewable energy consumption on economic growth: New evidence from the MENA Net Oil Exporting Countries (NOECs). Energy 116: 102-115

10. OECD (2017). Health at a Glance 2017: OECD Indicators. OECD Publishing. http://dx.doi.org/10.1787/health_glance-2017-en

11. Gouveia, N., \& Fletcher, T., (2000). Time series analysis of air pollution and mortality: effects by cause, age and socioeconomic status. Epidemiol Community Health, 54:750-755

12. Kelishadi, R., (2012). environmental pollution: health effects and operational implications for pollutants removal. Journal of Environmental and Public Health, 1-2. doi:10.1155/2012/341637

13. Kelishadi R. and Poursafa P., (2010). Air pollution and non-respiratory health hazards for children. Archives of Medical Science, 6(4), 483-495 
14. Machol, B.; \& Rizk, S. (2013). Economic value of U.S. fossil fuel electricity health impacts. Environmental International, 52, 75-80.

15. Ridker, R. (1967). Economic costs of air pollution: studies in measurement. New York: Praeger.

16. Ahmad, A., Zhao, Y., Shahbaz, M., Bano, S., Zhang, Z., Wang, S., \& Liu, Y. (2016). Carbon emissions, energy consumption and economic growth: an aggregate and disaggregate analysis of the Indian economy. Energy Policy, 96, 131-143.

17. Bouchoucha, N., (2020). The effect of environmental degradation on health status: do institutions matter? Journal of the Knowledge Economy, https://doi.org/10.1007/s13132-020-00680-y

18. Jian, Y., Messer, L. C., Jagai, J. S., Rappazzo, K. M., Gray, C. L., Grabich, S. C., \& Lobdell, D. T., (2017). Associations between environmental quality and mortality in the contiguous United States, 2000-2005. Environmental Health Perspectives, 125 (3), 355-362

19. Zanobetti A, \& Schwartz J. (2009). The effect of fine and coarse particulate air pollution on mortality: a national analysis. Environmental Health Perspectives 117:898-903

20. Tao Y, Huang W, Huang X, Zhong L, Lu SE, Li Y, et al. (2012). Estimated acute effects of ambient ozone and nitrogen dioxide on mortality in the Pearl River Delta of southern China. Environmental Health Perspective 120:393-398.

21. Krall JR, Anderson GB, Dominici F, Bell ML, \& Peng RD. (2013). Short-term exposure to particulate matter constituents and mortality in a national study of U.S. urban communities. Environmental Health Perspective 121:1148-1153

22. Campbell-Lendrum, D. \& Prüss-Ustün, A., (2019). Climate change, air pollution and noncommunicable diseases. Bulletin of the World Health Organization, 97: 160-161.

23. Pereira LC, de Souza AO, Bernardes MFF, Pazin M, Tasso MJ, Pereira PH, \& Dorta DJ (2015) A perspective on the potential risks of emerging contaminants to human and environmental health. Environmental Science and Pollution Research, 22(18), 13800-13823

24. Gao Y, Yang T, \& Jin J (2015) Nanoparticle pollution and associated increasing potential risks on environment and human health: a case study of China. Environmental Science and Pollution Research, 22(23):19297-19306

25. Anser, MK., Hanif, I., Vo, X. V., \& Alharthi, M., (2020). The long-run and short-run influence of environmental pollution, energy consumption, and economic activities on health quality in emerging countries. Environmental Science and Pollution Research, 27:32518-32532

26. Landrigan PJ, Fuller, R., Acosta, NJR. Adeyi, O., Arnold, R., Basu, N., Baldé, AB., Bertollini, R., \& Bose-O'Reilly, S. et al. (2018). The Lancet commission on pollution and health. Lancet 391:462512.

27. Lelieveld J, Evans JS, Fnais M, Giannadaki D, \& Pozzer A (2015) The contribution of outdoor air pollution sources to premature mortality on a global scale. Nature 525:367-371.

28. Lelieveld J., Klingmüller K., A. Pozzer, R. T., Haines, A., \& Ramanathan V. (2019). Effects of fossil fuel and total anthropogenic emission removal on public health and climate. PNAS,116(15), 157192-7197

29. Radmehr, R., Henneberry, S. R., \& Shayanmehr, S., (2021). Renewable energy consumption, $\mathrm{CO}_{2}$ emissions, and economic growth nexus: a simultaneity spatial modeling analysis of EU countries. Structural Change and Economic Dynamics, (2021), doi:https://doi.org/10.1016/j.strueco.2021.01.006

30. Coker, E. S., Cavalli, L., Fabrizi, E., Guastella, G., Lippo, E., Parisi, M. L., Pontarollo, N., Rizzati, M., Varacca, A., \& Vergall, S., (2020). The effects of air pollution on COVID-19 related mortality in Northern Italy. Environmental and Resource Economics, 76, 611-634

31. IPCC (2014). Climate Change 2014: Impacts, Adaptation, and Vulnerability: Working Group II Contribution to the Fifth Assessment Report. Cambridge University Press, Cambridge, UK and New York, NY USA

32. Sadorsky P (2009) Renewable energy consumption and income in emerging economies. Energy Policy 37:4021-4028

33. Bilgili F, Ozturk I, Kocak E, Bulut U, Pamuk Y, Mugaloglu E, \& Baglitas HH (2016) The influence of biomass energy consumption on $\mathrm{CO} 2$ emissions: a wavelet coherence approach. Environmental Science and Pollution Research, 23:19043-19061 
34. Smith. K. R., Frumkin, H., Balakrishnan, K., Butler, C. D., Chafe, ZA., Fairlie I., Kinney, P., Kjellstrom, T., Mauzerall, D., L., McKone, T. E., McMichael, A. J., \& Schneider, M., (2013). Energy and Human Health. Annual. Review of Public Health. 34:159-88

35. Pachauri S. (2011). Reaching an international consensus on defining modern energy access. Energy System, 3:235-40

36. Boardman B. (2010). Fixing Fuel Poverty: Challenges and Solutions. London: Earthscan

37. Howden-Chapman, P., Viggers H, Chapman R, O’Sullivan K, Barnard L, \& Lloyd B. (2011). Tackling cold housing and fuel poverty in New Zealand: a review of policies, research, and health impacts. Energy Policy 49:134-42

38. Cook JT, Frank DA, Casey PH, Rose-Jacobs R, \& Black MM, et al. (2008). A brief indicator of household energy security: associations with food security, child health, and child development in US infants and toddlers. Pediatrics 122: 867-75

39. Asghar, M. M., Wang, Z., Wang, B., \& Zaidi, S. A. H., (2020). Nonrenewable energy-environmental and health effects on human capital: empirical evidence from Pakistan. Environmental Science and Pollution Research, 27:2630-2646

40. Shobande, O. A., (2020). The effects of energy use on infant mortality rates in Africa. Environmental and Sustainability Indicators 5 (2020) 100015

41. Rasoulinezhad, E., Taghizadeh-Hesary, F., \& Taghizadeh-Hesary, F., (2020). How is mortality affected by fossil fuel consumption, $\mathrm{CO} 2$ emissions and economic factors in CIS region? Energies, 13, 2255; doi:10.3390/en13092255

42. Dogan, E., Ozturk, I. (2017). The influence of renewable and non-renewable energy consumption and real income on $\mathrm{CO} 2$ emissions in the USA: evidence from structural break tests. Environmental Science and Pollution Research, 10846-10854

43. Ali, S., Anwar, S., \& Nasreen, S., (2017). Renewable and non-renewable energy and its impact on environmental quality in South Asian countries. Forman Journal of Economic Studies, 13: 177-194

44. Zaidi SAH, Danish FH, Mirza FM (2018) The role of renewable and non-renewable energy consumption in $\mathrm{CO} 2$ emissions: a disaggregate analysis of Pakistan. Environmental Science and Pollution Research, 25(31):31616-31629

45. Hasnisah, A., Azlina, A. A., \& Taib, C. M. I. C., (2019). The impact of renewable energy consumption on carbon dioxide emissions: empirical evidence from developing countries in Asia. International Journal of Energy Economics and Policy, 9(3), 135-143

46. Hanif I, Raza SMF, Gago-de-Santos P, Abbas Q (2019) Fossil fuels, foreign direct investment, and economic growth have triggered $\mathrm{CO} 2$ emissions in emerging Asian economies: some empirical evidence. Energy, 171:493-501

47. Awodumi, O. B., \& Adewuyi, A. O. (2020). The role of non-renewable energy consumption in economic growth and carbon emission: Evidence from oil producing economies in Africa. Energy Strategy Reviews, 27, 100434. doi: 10.1016/j.esr.2019.100434

48. Chay, K. Y., \& Greenstone, M., (2003). The impact of air pollution on infant mortality: evidence from geographic variation in pollution shocks induced by a recession. The Quarterly Journal of Economics, 118(3), 1121-1167.

49. Fotourehchi, Z. (2016). Health effects of air pollution: An empirical analysis for developing Countries. Atmospheric Pollution Research,7, 201- 206.

50. Mutizwa, A., \& Makochekanwa, A., (2015). Impact of environmental quality on health status: a study of 12 Southern African Development Community (SADC) Countries between 2000 and 2008. BOJE: Botswana Journal of Economics, 13(1), 87-111

51. Sinha, A. (2014). Carbon emissions and mortality rates: a causal analysis for India (1971-2010). International Journal of Economic Practices and Theories, 4(4): 486-492.

52. Adedotun, A.F., Obadina O.G., Adesina O.S., Omosanya K.O., \& Dare, R.J. (2018). Statistical analysis of the effect of environmental degradation on mortality rate: a vector autoregressive (VAR) model approach. International Journal of Science and Engineering Invention, 04(11), 5-14

53. MacKinnon, David P., Fairchild, Amanda J. and Fritz, Matthew S. (2007) Mediation Analysis. Annual Review of Psychology 58(1), 593-614

54. Baron RM, Kenny DA. 1986. The moderator-mediator variable distinction in social psychological research: conceptual, strategic, and statistical considerations. J. Personal. Soc. Psychol. 51:1173-82 
55. Kenny DA, Kashy DA, Bolger N. 1998. Data analysis in social psychology. In The Handbook of Social Psychology, Volume 1, ed. DT Gilbert, ST Fiske, G Lindzey, pp. 233-65. New York: Oxford Univ. Press

56. Judd CM, \& Kenny DA. (1981a). Estimating the Effects of Social Interventions. Cambridge, UK: Cambridge Univ. Press

57. Judd CM, Kenny DA. 1981b. Process analysis: estimating mediation in treatment evaluations. Eval. Rev. 5:602-19

58. Aigner, D. J. and Goldberger. A. S. (eds.) (1977). Latent Variables in Socioeconomic Models. Amsterdam: North-Holland.

59. Goldberger, A. S. \& Duncan, 0. D. (1973). Structural Equation Models in the Social Sciences. New York: Seminar Press.

60. Saris, W. E. \& Stronkhorst, L. H. (1984). Causal Modeling in None.rperimerttul Research: An Introduction to LISREL Analysis, Amsterdam: Sociometric Research Foundation.

61. Saris, W. E. (1980). Linear Structural Relationships. Quality and Quantity 14, 205-225.

62. Anderson, T. W. (1984). "Estimating linear statistical relationships", Annals of Statistics 12: 1-42.

63. Jöreskog, K. G. (1981). "Analysis of covariance structures”. Scandinavian Journal of Statistics 8: 65-92.

64. Bentler, P. M. (1986). "Structural modeling and Psychometrika: An historical perspective on growth and achievements", Psychometrika 51: 35-51.

65. Satorra, A. (1990) Robustness issues in structural equation modeling: a review of recent developments. Quality \& Quantity 24, 367-386 (1990). https://doi.org/10.1007/BF00152011

66. Hayes, A. F. (2009). Beyond Baron and Kenny: Statistical mediation analysis in the new millennium. Communication Monographs, 76, 408-420.

67. Hayes, A.F., 2013. Introduction to Mediation, Moderation, and Conditional Process Analysis: A Regression Based Approach, 1 ed. Guilford Publications, New York.

68. Edelman, L.F., Brush, C.G., Manolova, T., 2005. Co-alignment in the resource performance relationship: strategy as mediator. Journal of Business Venturing 20, 359e383. https://doi.org/10.1016/j.jbusvent.2004.01.004

69. Hojnik, J., Ruzzier, M., and Manolova, T. S. (2018). Internationalization and economic performance: The mediating role of eco-innovation. Journal of Cleaner Production, 171 (2018) 1312-1323. doi:10.1016/j.jclepro.2017.10.111

70. Cheung, G. W., \& Lau, R. S. (2008). Testing mediation and suppression effects of latent variables: Bootstrapping with structural equation models. Organizational Research Methods, 11, 296e325.

71. Anderson, J., \& Gerbing, D. (1988). Structural equation modeling in practice: A review and recommended two-step approach. Psychological Bulletin, 103, 411-423

72. Bentler, P. M. (1990). Comparative fit indexes in structural models. Psychological Bulletin, 107, 238-246. https://doi.org/10.1037/0033-2909.107.2.238

73. Bentler, P.M., \& Bonett, D. G. (1980). Significance tests and goodness of fit in the analysis of covariance structures. Psychological Bulletin, 88, 588-606. https://doi.org/10.1037/0033909.88.3.588

74. Tucker, L. R., \& Lewis, C. (1973). A reliability coefficient for maximum likelihood factor analysis. Psychometrika, 38, 1-10.

75. Steiger, J. H. (1990). Structural model evaluation and modification: An interval estimation approach. Multivariate Behavioral Research, 25, 173-180.

76. Steiger, J. H., \& Lind, J. C. (1980). Statistically based tests for the number of common factors. Paper presented at the Annual Meeting of the Psychometric Society, Iowa City, IA.

77. Nathaniel S., and Adeleye, N. (2021). "Environmental preservation amidst carbon emissions, energy consumption and urbanization in selected African countries: Implications for sustainability." Journal of Cleaner Production 285 (2021) 125409 https://doi.org/10.1016/j.jclepro.2020.125409

78. Adeleye, B. N., Akam, D., Inuwa, N., Olarinde, M., and Okafor, V. (2021). Investigating growthenergy-emissions trilemma in South Asia. International Journal of Energy Economics and Policy (Accepted, Forthcoming).

79. Hu, L., \& Bentler, P. M. (1999). Cutoff criteria for fit indexes in covariance structure analysis: Conventional criteria versus new alternatives. Structural Equation Modeling, 6, 1-55. https://doi.org/10.1080/10705519909540118 


\section{Appendix}

Table A1 List of Countries and Classifications

\begin{tabular}{|c|c|c|c|}
\hline S/No. & Country & Sub-Region & Income Group \\
\hline 1 & Australia & East Asia \& Pacific & High Income \\
\hline 2 & Bangladesh & South Asia & Lower-Middle Income \\
\hline 3 & Bhutan & South Asia & Lower-Middle Income \\
\hline 4 & Brunei Darussalam & East Asia \& Pacific & High Income \\
\hline 5 & Cambodia & East Asia \& Pacific & Lower-Middle Income \\
\hline 6 & China & East Asia \& Pacific & Upper-Middle Income \\
\hline 7 & Fiji & East Asia \& Pacific & Upper-Middle Income \\
\hline 8 & Hong Kong SAR, China & East Asia \& Pacific & High Income \\
\hline 9 & India & South Asia & Lower-Middle Income \\
\hline 10 & Indonesia & East Asia \& Pacific & Upper-Middle Income \\
\hline 11 & Japan & East Asia \& Pacific & High Income \\
\hline 12 & Kazakhstan & Central Asia & Upper-Middle Income \\
\hline 13 & Kiribati & East Asia \& Pacific & Lower-Middle Income \\
\hline 14 & Korea, Rep. (South) & East Asia \& Pacific & High Income \\
\hline 15 & Kyrgyz Republic & Central Asia & Lower-Middle Income \\
\hline 16 & Lao PDR & East Asia \& Pacific & Lower-Middle Income \\
\hline 17 & Macao SAR, China & East Asia \& Pacific & High Income \\
\hline 18 & Malaysia & East Asia \& Pacific & Upper-Middle Income \\
\hline 19 & Maldives & South Asia & Upper-Middle Income \\
\hline 20 & Marshall Islands & East Asia \& Pacific & Upper-Middle Income \\
\hline 21 & Micronesia, Fed. Sts. & East Asia \& Pacific & Lower-Middle Income \\
\hline 22 & Mongolia & East Asia \& Pacific & Lower-Middle Income \\
\hline 23 & Myanmar & East Asia \& Pacific & Lower-Middle Income \\
\hline 24 & Nauru & East Asia \& Pacific & High Income \\
\hline 25 & Nepal & South Asia & Lower-Middle Income \\
\hline 26 & New Zealand & East Asia \& Pacific & High Income \\
\hline 27 & Pakistan & South Asia & Lower-Middle Income \\
\hline 28 & Palau & East Asia \& Pacific & High Income \\
\hline 29 & Papua New Guinea & East Asia \& Pacific & Lower-Middle Income \\
\hline 30 & Philippines & East Asia \& Pacific & Lower-Middle Income \\
\hline 31 & Samoa & East Asia \& Pacific & Upper-Middle Income \\
\hline 32 & Singapore & East Asia \& Pacific & High Income \\
\hline 33 & Solomon Islands & East Asia \& Pacific & Lower-Middle Income \\
\hline 34 & Sri Lanka & South Asia & Lower-Middle Income \\
\hline 35 & Taiwan, China & East Asia \& Pacific & High Income \\
\hline 36 & Timor-Leste & East Asia \& Pacific & Lower-Middle Income \\
\hline 37 & Tonga & East Asia \& Pacific & Upper-Middle Income \\
\hline 38 & Turkmenistan & Central Asia & Upper-Middle Income \\
\hline 39 & Tuvalu & East Asia \& Pacific & Upper-Middle Income \\
\hline
\end{tabular}




$\begin{array}{llll}40 & \text { Uzbekistan } & \text { Central Asia } & \text { Lower-Middle Income } \\ 41 & \text { Vanuatu } & \text { East Asia \& Pacific } & \text { Lower-Middle Income } \\ 42 & \text { Vietnam } & \text { East Asia \& Pacific } & \text { Lower-Middle Income }\end{array}$

Source: Authors' Compilations

Table A2 Summary Statistics - Full Sample and Income Groups

\begin{tabular}{|c|c|c|c|c|c|c|c|c|}
\hline \multirow[b]{2}{*}{ Variable } & \multicolumn{4}{|c|}{ Full Sample } & \multicolumn{4}{|c|}{ High Income Countries } \\
\hline & Mean & $\begin{array}{l}\text { Std. } \\
\text { Dev. }\end{array}$ & Min & Max & Mean & $\begin{array}{l}\text { Std. } \\
\text { Dev. }\end{array}$ & Min & Max \\
\hline MINF & 27.074 & 16.916 & 2.1 & 79 & 12.903 & 13.16 & 2.1 & 47.4 \\
\hline MU5 & 33.272 & 21.715 & 2.7 & 99.8 & 15.211 & 15.44 & 2.7 & 56.2 \\
\hline ENUPC & 2079.991 & 2182.923 & 58.046 & 9837.447 & 4297.067 & 2276.238 & 283.493 & 9837.447 \\
\hline $\mathrm{CO} 2 \mathrm{PC}$ & 4.17 & 5.123 & 0.098 & 24.627 & 9.102 & 5.823 & 0.305 & 24.627 \\
\hline BSAN & 73.784 & 24.905 & 14.131 & 100 & 95.196 & 10.225 & 65.596 & 100 \\
\hline SECF & 78.246 & 23.569 & 26.892 & 145.888 & 95.407 & 17.481 & 50.082 & 145.888 \\
\hline \multicolumn{5}{|c|}{ Lower-Middle Income Countries } & \multicolumn{4}{|c|}{ Upper-Middle Income Countries } \\
\hline Variable & Mean & $\begin{array}{l}\text { Std. } \\
\text { Dev. }\end{array}$ & Min & Max & Mean & $\begin{array}{c}\text { Std. } \\
\text { Dev. }\end{array}$ & Min & Max \\
\hline MINF & 36.402 & 15.009 & 7.5 & 79 & 21.708 & 11.837 & 6.7 & 57.8 \\
\hline MU5 & 45.49 & 19.909 & 8.8 & 99.8 & 25.835 & 14.435 & 7.9 & 70.2 \\
\hline ENUPC & 564.614 & 446.598 & 58.046 & 1828.103 & 2315.542 & 1584.675 & 315.133 & 4893.41 \\
\hline $\mathrm{CO} 2 \mathrm{PC}$ & 1.215 & 1.811 & 0.098 & 15.139 & 4.612 & 4.492 & 0.69 & 15.646 \\
\hline BSAN & 55.902 & 22.206 & 14.131 & 100 & 87.186 & 11.938 & 50.504 & 99.557 \\
\hline SECF & 63.815 & 22.084 & 26.892 & 101.77 & 87.838 & 12.188 & 59.839 & 115.764 \\
\hline
\end{tabular}

Note: $* * *$ denotes statistical significance at the $1 \%$ level; MINF $=$ infant mortality rates; MU5 = under-5 mortality rate; $\mathrm{CO} 2 \mathrm{PC}=$ carbon emissions per capita; $\mathrm{ENUPC}=$ nonrenewable energy per capita; $\mathrm{BSAN}=$ access to basic sanitation; SECF $=$ female secondary school enrolment; $1 \mathrm{n}=$ natural logarithm.

Source: Authors' Computations

Table A3 Correlation Analysis

\begin{tabular}{lcccccc}
\hline Variables & 1 & 2 & 3 & 4 & 5 & 6 \\
\hline (1) $\ln$ MINF & 1.000 & & & & & \\
(2) $\ln$ MUS & $0.998^{* * *}$ & 1.000 & & & & \\
(3) $\operatorname{lnCO} 2 \mathrm{PC}$ & $-0.643^{* * *}$ & $-0.655^{* * *}$ & 1.000 & & & \\
(4) $\operatorname{lnENUPC}$ & $-0.712^{* * *}$ & $-0.712^{* * *}$ & $0.948^{* * *}$ & 1.000 & & \\
(5) $\operatorname{lnSECF}$ & $-0.690^{* * *}$ & $-0.701 * * *$ & $0.634^{* * *}$ & $0.640^{* * *}$ & 1.000 & \\
(6) $\operatorname{lnBSAN}$ & $-0.563 * * *$ & $-0.581^{* * *}$ & $0.626 * * *$ & $0.701 * * *$ & $0.750 * * *$ & 1.000 \\
\hline
\end{tabular}

Note: $* * * * *$, and $*$ denote statistical significance at the $1 \%, 5 \%$, and $10 \%$ levels, respectively; ln $=$ natural logarithm; $\mathrm{MINF}=$ infant mortality rates; $\mathrm{MU} 5=$ under -5 mortality rate $; \mathrm{CO} 2 \mathrm{PC}=$ carbon emissions per capita; ENUPC = nonrenewable energy per capita; $\mathrm{SECF}=$ female secondary school enrolment; BSAN = access to basic sanitation.

Source: Authors' Computations

Table A4 Full Sample and Income Groups, Robustness Results

\begin{tabular}{|c|c|c|c|c|}
\hline Variables & Main & High Income & $\begin{array}{l}\text { Lower-Mid } \\
\text { Inc }\end{array}$ & Upper-Mid Inc \\
\hline
\end{tabular}


$[1]$

[2]

[3]

[4]

Structural Model: Dep. Var: $\ln C O 2 P C$

\begin{tabular}{|c|c|c|c|c|}
\hline $\operatorname{lnENUPC}$ it & $\begin{array}{c}1.1309 * * * \\
(32.59)\end{array}$ & $\begin{array}{c}1.2313 * * * \\
(135.81)\end{array}$ & $\begin{array}{c}1.0841 * * * \\
(10.88)\end{array}$ & $\begin{array}{c}1.0830 * * * \\
(28.05)\end{array}$ \\
\hline Constant & $\begin{array}{c}-7.1204 * * * \\
(-26.77)\end{array}$ & $\begin{array}{c}-8.1194 * * * \\
(-117.27)\end{array}$ & $\begin{array}{c}-6.8692 * * * \\
(-10.71)\end{array}$ & $\begin{array}{c}-6.5135 * * * \\
(-21.51)\end{array}$ \\
\hline \multicolumn{5}{|c|}{ Regression Model: Dep. Var: $\ln M U 5$} \\
\hline $\operatorname{lnENUPC}_{\text {it }}$ & $\begin{array}{c}-0.5106 * * * \\
(-7.62)\end{array}$ & $\begin{array}{c}0.3124 \\
(0.99)\end{array}$ & $\begin{array}{c}-0.0267 \\
(-0.23)\end{array}$ & $\begin{array}{c}-0.7809 * * \\
(-2.16)\end{array}$ \\
\hline $\operatorname{lnCO} 2 \mathrm{PC}_{\mathrm{it}}$ & $\begin{array}{l}0.0759 \\
(1.46)\end{array}$ & $\begin{array}{c}-0.5101 * * \\
(-2.06)\end{array}$ & $\begin{array}{c}0.1029 * \\
(1.73)\end{array}$ & $\begin{array}{c}0.5604 * * \\
(2.00)\end{array}$ \\
\hline $\operatorname{lnSECF}$ it & $\begin{array}{c}-0.8126 * * * \\
(-7.65)\end{array}$ & $\begin{array}{c}0.8223 * * * \\
(2.94)\end{array}$ & $\begin{array}{c}-0.7375 * * * \\
(-6.13)\end{array}$ & $\begin{array}{l}0.7640 \\
(1.27)\end{array}$ \\
\hline $\operatorname{lnBSAN} \mathrm{it}_{\mathrm{it}}$ & $\begin{array}{c}-0.0446 \\
(-0.34)\end{array}$ & $\begin{array}{c}-24.1973 * * * \\
(-19.92)\end{array}$ & $\begin{array}{r}-0.2137 \\
(-1.63)\end{array}$ & $\begin{array}{c}-2.0654 * * * \\
(-6.31)\end{array}$ \\
\hline Constant & $\begin{array}{c}10.3436^{* * * *} \\
(12.09)\end{array}$ & $\begin{array}{c}107.7152^{* * * *} \\
(20.48)\end{array}$ & $\begin{array}{c}7.8778^{* * * *} \\
(8.68)\end{array}$ & $\begin{array}{c}13.5719 * * * \\
(5.22)\end{array}$ \\
\hline Observations & 171 & 171 & 171 & 171 \\
\hline Log-likelihood & -563.36 & -148.98 & -148.98 & -148.98 \\
\hline Wald Test (lnCO2PC) & $1062.16^{* * *}$ & $18445.12^{* * *}$ & $118.37 * * *$ & $786.65 * * *$ \\
\hline Wald Test (lnMINF) & $341.91 * * *$ & $1731.64 * * *$ & $69.11 * * *$ & $162.94 * * *$ \\
\hline
\end{tabular}

Note: $* * *, * *$, and $*$ denote statistical significance at the $1 \%, 5 \%$, and $10 \%$ levels, respectively;

Estimations with Satorra-Bentler standard errors; $\ln =$ natural logarithm; MINF $=$ infant mortality rates;

MU5 = under-5 mortality rate; $\mathrm{CO} 2 \mathrm{PC}=$ carbon emissions per capita; $\mathrm{ENUPC}=$ nonrenewable energy

per capita; $\mathrm{SECF}=$ female secondary school enrolment; BSAN = access to basic sanitation.

Source: Authors' Computations

Table A5 Decomposition of Effects and Diagnostics, Robustness

\begin{tabular}{lcccc}
\hline \multirow{2}{*}{ Nonrenewable energy consumption } & Full Sample & High & Lower-mid & Upper-mid \\
\cline { 2 - 5 } & Standardized & Standardized & Standardized & Standardized \\
\hline Direct Effects & $-0.511^{* * *}$ & 0.312 & -0.027 & -0.781 \\
Z stat & $(-7.62)$ & $(0.99)$ & $(-0.23)$ & $(-2.16)$ \\
Mediation Effects & 0.858 & $-0.628^{* *}$ & $0.112^{*}$ & $0.607^{* *}$ \\
Z stat & $(1.46)$ & $(-2.05)$ & $(1.87)$ & $(2.06)$ \\
Total Effects & $-0.425^{* * *}$ & $-0.316^{* * *}$ & 0.085 & $-0.174^{*}$ \\
z stat & $(-10.05)$ & $(-14.83)$ & $(1.04)$ & $(1.86)$ \\
\hline Diagnostics/Goodness-of-fit & Full Sample & Income Groups \\
\hline RMSEA & 0.016 & & 0.018 \\
Comparative fit index (CFI) & 0.994 & & 0.981 & \\
Tucker-Lewis index (TLI) & 0.980 & & 0.934 & \\
Standardized root mean squared residual & 0.018 & & 0.042 & \\
Coefficient of determination (CD) & 0.922 & & \\
\hline
\end{tabular}

Note: $* * * * *$, and $*$ denote statistical significance at the $1 \%, 5 \%$, and $10 \%$ levels, respectively; Estimations with Satorra-Bentler standard errors; RMSEA: Root mean squared error of approximation.

Source: Authors' Computations 